\title{
IDENTIFYING OF HUMAN METAPNEUMOVIRUS AND ITS PHENOTYPE AS A CAUSATIVE AGENTS OF PNEUMONIA IN CHILDREN
}

\author{
ABBAS MOHAMMED HUSSEIN AL-SHEBANI ${ }^{1 *}$, ADNAN HAMAD AUBAID ${ }^{2}$ \\ ${ }^{1}$ Department of Pediatrics, College of Medicine, University of Al-Qadisiyah, Iraq. ${ }^{2}$ Department of Medical Microbiology, College of Medicine, \\ University of Al-Qadisiyah, Iraq. E-mail: aba.alshebani70@gmail.com \\ Received: 01 February 2017, Revised and Accepted: 20 February 2018
}

\section{ABSTRACT}

Objectives: The present investigational study was aimed to detect and identify the genotypes of Human metapneumovirus (hMPV) and its phylogeny with respiratory syncytial viruses (RSV) that cause pulmonary inflammation.

Material and Methods: A total of 250 samples of patients who were clinically diagnosed respiratory tract illness were collected from Maternity and Children Hospital in Al Diwaniyah city, Iraq. The clinical samples were nasopharyngeal, nasal and throat swabs. The current study screened the presence of hMPV and RSV (A and B) genotypes from nasopharyngeal specimens of children aged from several days to 10 years old.

Results: The results revealed that $6 \%$ were infected with $h M P V, 8 \%$ of respiratory syncytial viruses type $A$ (RSV-A) and $14 \%$ of respiratory syncytial virus's type $B(R S V-B)$ from children who are suffering from respiratory illness. Phylogenetic tree analysis of hMPV based on the partial sequences of the fusion protein $(F)$ gene was used for genotyping and detection. The phylogenetic tree was constructed using maximum likelihood tree method in MEGA 6.0 version. The local $h M P V$ isolates (S1) were closely related to NCBI-Blast $h M P V$ genotype A1 (KM408076.1), the local $h M P V$ isolates (S2, S3, and S5) were closely related to NCBI-Blast $h M P V$ genotype B1 (KJ196323.1), and the local $h M P V$ isolates (S4) were closely related to NCBI-Blast $h M P V$ genotype B2 (JQ041689.1).

Conclusions: The prevalence rate of $h M P V$ is less than RSV, and both subtypes of $h M P V, \mathrm{~A}$ and B may exist and circulate in one season, and the predominant sublineage of $h M P V$ shifts in progressive season.

Keywords: DNA, Sequencing, Human metapneumovirus, Phylogenetic tree, Respiratory syncytial virus

(c) 2018 The Authors. Published by Innovare Academic Sciences Pvt Ltd. This is an open access article under the CC BY license (http://creativecommons. org/licenses/by/4. 0/) DOI: http://dx.doi.org/10.22159/ajpcr.2018.v11i4.25578

\section{INTRODUCTION}

Human metapneumovirus (hMPV) infection was recognized and isolated in 2001 by specialists from the Netherlands, van den Hoogen et al. They observe this infection by investigating the cytopathic impact on cell society in tertiary monkey kidney cells [1] of nasopharyngeal aspirate from children who have got respiratory syndromes such as common cold, bronchiolitis, and asthma exacerbation [2-4].

The $h M P V$ is an enveloped, single-strand, negative-sense RNA virus belonging to the family Paramyxoviridae, subfamily Pneumovirinae, and genus metapneumovirus. The $h M P V$ has been classified into two genotypes: A and Nucleotides and amino acid sequence identities between the $h M P V$ groups are $80 \%$ and $90 \%$, respectively, each of them has two siblings: A1(NL 00-1 like), A2 (NL 93-1 like); B1(NL 99-1 like); and B2 (NL 94-1 like) [1]. The $h M P V$ as other members of the Paramyxoviridae is a typically spherical, enveloped with a diameter of 150-200 nm. Another shape can be present such as filamentous with diameter 100-400 $\mathrm{nm}$ and pleomorphic. A lipid envelope that derived from the plasma membrane of infected cells surround the virus particles. The lipid layer of the $h M P V$ is very vulnerable to organic chemical agents [5].

There are three virus glycoproteins on the viral envelope, glycoprotein $\mathrm{G}$ for attachment, $\mathrm{F}$ for fusion and small hydrophobic protein [6]. Glycoprotein G inside external carboxy-terminal components and inside internal amino acid, and while $\mathrm{F}$ protein with the amino terminus is located outside the virus particle and a short cytoplasmic carboxyl-terminal positioned inside part of the viral envelope. The $\mathrm{G}$ and $\mathrm{F}$ proteins composed of 10 to $14-\mathrm{nm}$ spikes on the surface of virion, and it is strongest related to the avian metapneumovirus type $C$, formerly turkey rhinotracheitis virus, these two viruses have been classified into a distinct genus, metapneumovirus [2]. The genomic RNA of $h M P V$ associated with the viral glycoprotein $(\mathrm{N})$, large (L) proteins, and the phosphoprotein (P) to produce the "helical nucleocapsid" which is situated inside M-protein that produces a linkage between the nucleocapsid and envelope of the virion. The M2-1 transcriptional enhancer protein is also thought to be related to the nucleocapsid [7]. The universal circulation forms of $h M P V$ are inconstant and sophisticated. Recently, the epidemics of $h M P V$ are extremely restricted and public-dependent despite the frequency of $h M P V$ infection differ annually. Both genotypes strains, all sub-genotypes, and lineages may stream concomitantly in a particular position during a particular period $[8,9]$. In addition, the worldwide and localized $h M P V$ epidemics can differ yearly which dominating circulating strains. Global effective vaccine of $h M P V$ required understanding the genetic heterogeneity of the strain [10]. Hence, the present study was aimed to detect, identify the genotype $h M P V$ and its phylogeny with respiratory syncytial viruses $(R S V)$ that cause pulmonary inflammation.

\section{MATERIALS AND METHODS}

\section{Samples collection}

Informed consent was obtained from all patients, and the project was approved by the College of Medicine, University of Al-Qadisiyah Ethics Committee.

The current study was carried out in College of Medicine laboratories, University of Al-Qadisiyah, Iraq, in the period from December 2014 to December 2015. 230 samples of patients who were clinically diagnosed respiratory tract illness were collected from Maternity and Children hospital in Al Diwaniyah city, Iraq. Information of each patient was 
recorded through a questionnaire format which has been constructed by the supervisors and pediatricians. The questionnaire included the name of the patient, age, gender and the major clinical features such as fever, cough, vomiting, and nasal discharge (rhinorrhea illness). The clinical samples were nasopharyngeal, nasal and throat swabs. The samples were collected in vials containing viral transport media which prepared for this purpose, then transported to the laboratory for storage at $-70^{\circ} \mathrm{C}$ until use.

\section{Reverse transcription quantitative polymerase chain reaction (RT-} qPCR)

Viral RNA was extracted from frozen nasopharyngeal swabs using AccuZolTM total RNA extraction kit (Bioneer, South Korea) and prepared based on manufacturer's instructions. To duplicate a piece of the "open reading frames (ORFs)" of the F. gene, the RT-qPCR set and used. The primers and probe were designed in this study using complete sequence of nucleoprotein gene RSV-A (GenBank: KF973340.1), RSV-B (GenBank: KF893260.1), and $h P M V$ (GenBank: KF891365.1) from NCBI-GenBank and Primer3 plus design. The primers were supplied by Bioneer Company, South Korea, as revealed in Table 1.

RT-qPCR was performed for detection of respiratory syncytial virus type $A n(R S V-A)$, respiratory syncytial virus type $B(R S V-B)$ and human metapneumovirus based on nucleoprotein gene and this technique were carried out according to the method described by manufacturer's instructions. RT-PCR master mix was prepared according to manufacturer's instructions of Bioneer company, South Korea, as shown in Table 2.

The RT-PCR master mix reaction constituents that stated in Table 2 were supplemented into RT-PCR tube containing ( 8 wells strips tubes which containing Rocketscript reverse transcriptase and TaqMan probe premix). Then, all strips tubes vortexing for mixing the components and centrifuged (3000 rpm for $3 \mathrm{~min}$ in an Existing centrifuge), next to that moved into real-time PCR thermocycler. The conditions of real-time PCR thermocycler were set based on the temperature of primer annealing and RT-PCR TaqMan instructions of kit as revealed in Table 3 .

The data of RT-qPCR of target and housekeeping genes were examined by the comparative quantification gene expression levels (fold change) that designated by Livak and Schmittgen (2001). The DNA sequencing was performed for genotyping of $h M P V$ based on F-fusion gene. The PCR product of hMPV F-gene (428 bp) was refined from agarose gel using the EZ-10 Spin column DNA Gel Extraction kit (Bio Basic, Canada). After that, the refined F-gene was directed to Bioneer company (South Korea) for conduction the DNA sequencing.

\section{Phylogenetic tree}

Consensus sequences were generated using MEGA 6.0, multiple alignment analysis tools. The sequences nucleotide belongs to normal species from the both " $h M P V$ genotypes and sub-lineages" were gained from "NCBI-GenBank human metapneumovirus" based ClustalW alignment analysis of fusion protein (F) gene and used to constitute both phylogeny and alignments.

\section{RESULTS AND DISCUSSION}

The results revealed that only $7 \%$ were encountered with the hMPV, $8 \%$ and 14\% were detected with RSV-A and B genotypes, respectively [Fig.s 1-3]. There are several studies revealed different results of detected of hMPV, the lowest prevalence has been reported in Cambodia, 1.7\%, and 2.6\%\% in the USA and the highest prevalence rate reported was $54.4 \%$ in Al-Ahwaz province [11-13] while the prevalence rate of RSV was $29.3 \%$ in infants with median age 13.5 months as in the study of [14]

In the subsequent study, it deliberated certain the genetic variation (genotyping) of human metapneumovirus to divulge the only five

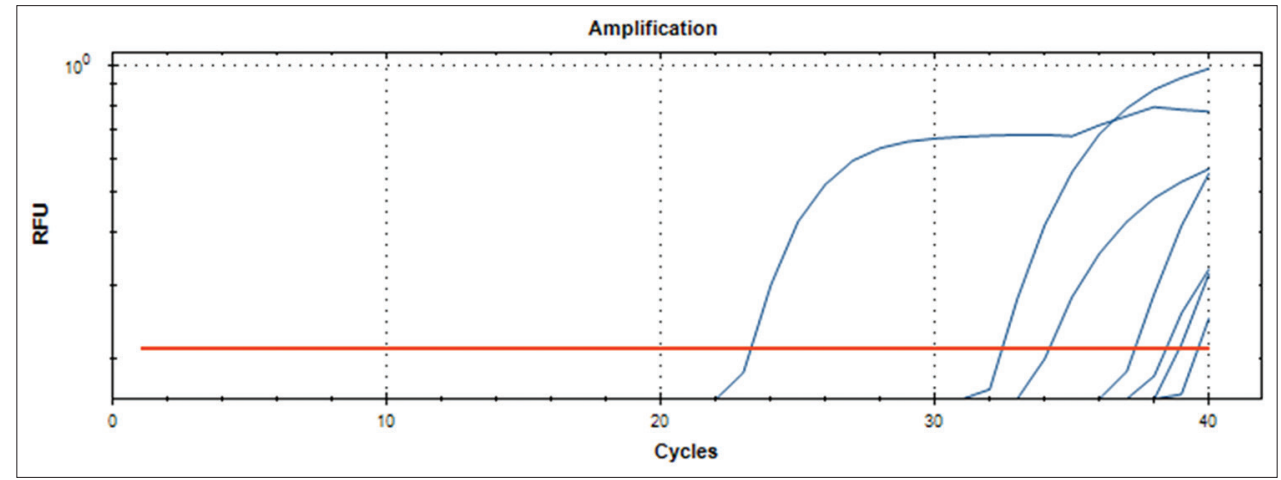

Fig. 1: Real-time polymerase chain reaction amplification plot of positive samples for human metapneumovirus based nucleoprotein gene primers and probe (FAM) dye of nasopharyngeal swabs, where the positive samples were shown positive amplification ranging from 23.24 into 39.56 threshold cycle (CT)

Table 1: Primers of F gene used in this study

\begin{tabular}{|c|c|c|}
\hline Primer & Sequence(" $5 \rightarrow 3$ ") & Amplicon size \\
\hline \multirow[t]{2}{*}{ RSV-A primer } & TGCAGGGCAAGTGATGTTAC & $86 \mathrm{bp}$ \\
\hline & TTTCTGCTTGCACACTAGCG & \\
\hline RSV-A probe & VIC-GGTGGGGAGTCTTAGCAAAATCAGTT-BHQ-1 & \\
\hline \multirow[t]{2}{*}{ SV-B } & F $\quad$ TGTGCACTTTGGCATTGCAC & \\
\hline & $\begin{array}{ll}\mathrm{R} & \text { TTACTTGCCCTGAACCATAGG C }\end{array}$ & $101 \mathrm{bp}$ \\
\hline RSV-B probe & NED-TCCACAAGAGGGGGTAGTAGAGTTGA- BHQ-1 & \\
\hline HMPV primer & $\begin{array}{ll}\mathrm{F} & \text { AGAAACTCAGGCAGTGAAGTC C } \\
\mathrm{R} & \text { TCTCTTCCACCCAGCTTTTCTC }\end{array}$ & $130 \mathrm{bp}$ \\
\hline HMPV probe & & \\
\hline
\end{tabular}

F: Forward; R: Reverse, HMPV: Human metapneumovirus, RSV: Respiratory syncytial viruses, RSV-A: Respiratory syncytial viruses-Type A, RSV-B: Respiratory syncytial viruses-Type B 


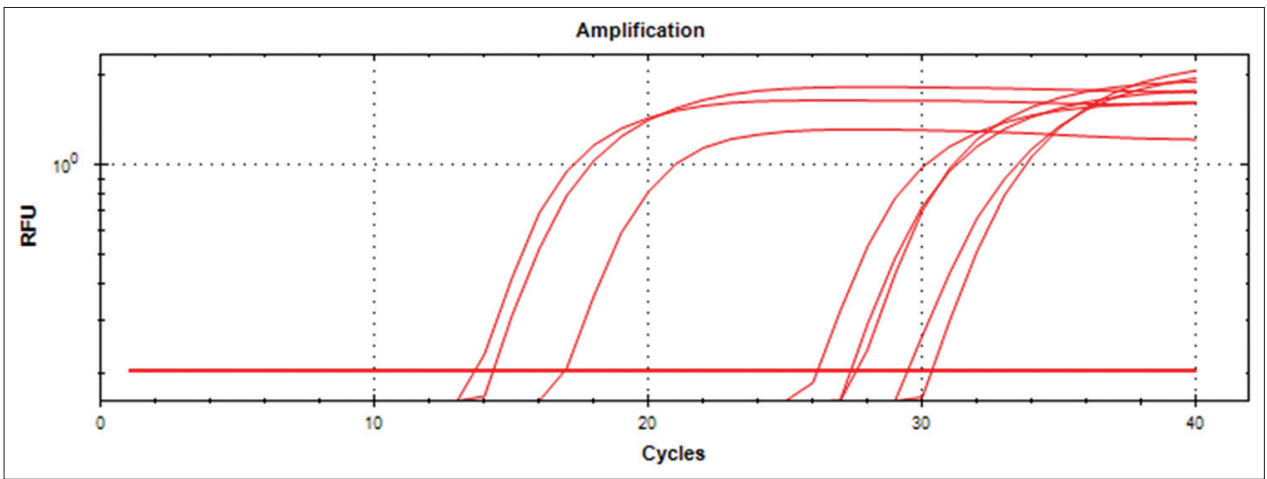

Fig. 2: Real-time polymerase chain reaction amplification plot of positive samples for Human respiratory syncytial virus type A based nucleoprotein gene primers and probe (VIC) dye in nasopharyngeal swabs samples, where the positive samples were shown positive amplification ranging from 13.79 to 30.28 threshold cycle (CT)

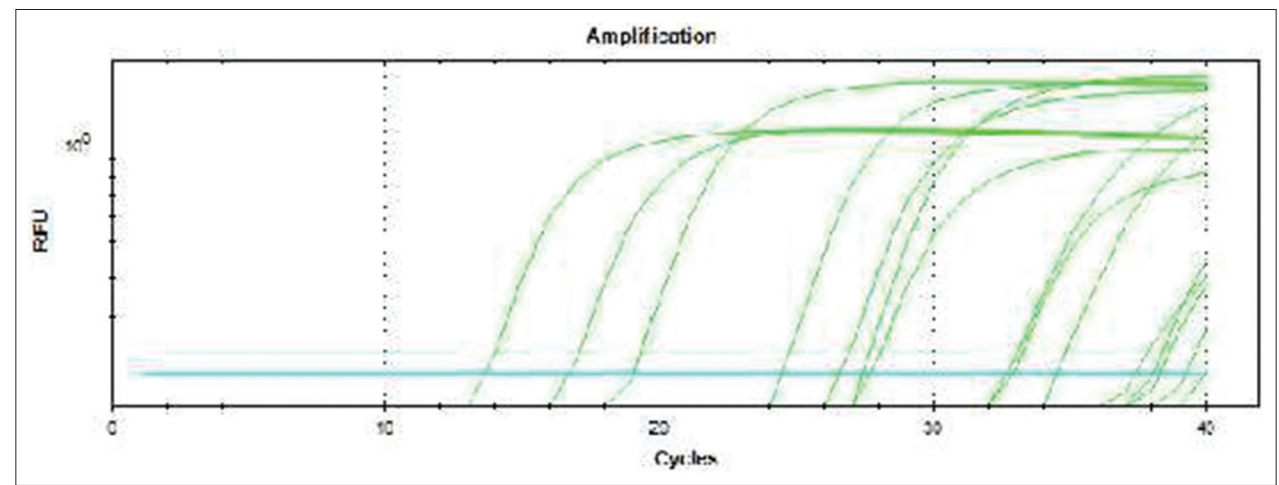

Fig. 3: Real-time polymerase chain reaction amplification plot of positive samples for Human respiratory syncytial virus type B based nucleoprotein gene primers and probe (NED) dye in the nasopharyngeal swab samples where the positive samples were shown positive amplification ranging from 13.72 to 39.94 threshold cycle (CT)

Table 2: Components of PCR master mix

\begin{tabular}{ll}
\hline RT-PCR master mix & Volume $(\mu \mathbf{L})$ \\
\hline Total RNA template & 5 \\
RSV-A, RSV-B, HMV & 2.5 \\
$\begin{array}{l}\text { Forward primer (20 pmol) } \\
\text { RSV-A, RSV-B, HMV }\end{array}$ & \\
$\begin{array}{l}\text { Reverse primer (20 pmol) } \\
\text { RSV-A, RSV-B, HMV } \\
\text { probe (25pmol) }\end{array}$ & 2.5 \\
DEPC water & 2.5 \\
Total & 37.5 \\
\hline
\end{tabular}

RT-PCR: Reverse transcription polymerase chain reaction, RSV-A: Respiratory syncytial viruses-Type A, RSV-B: Respiratory syncytial viruses-Type B

Table 3: RT-PCR thermocycler conditions

\begin{tabular}{lll}
\hline Step & Conditions & Cycle \\
\hline Reverse transcriptase & $50^{\circ} \mathrm{C}, 15 \mathrm{~min}$ & 1 \\
Pre-denaturation & $95^{\circ} \mathrm{C}, 5 \mathrm{~min}$ & 1 \\
$\begin{array}{l}\text { Denaturation } \\
\text { Annealing/extension }\end{array}$ & $95^{\circ} \mathrm{C}, 20 \mathrm{~s}$ & \\
Detection (scan) & $60^{\circ} \mathrm{C}, 30 \mathrm{~s}$ & \\
\hline
\end{tabular}

RT-PCR: Reverse transcription polymerase chain reaction

local isolates and align with the reference isolates that have been brought from NCBI-GenBank human metapneumovirus and revealed distinctiveness of particular isolates, beyond that, this section will focus on the comparison with other studies in different countries and different places, and they will have known the predominant strain (genotype) of human metapneumovirus, at the end of these papers would be doing to determine the cause of the predominance local isolates [Fig. 4]

The aforementioned sequence alignment of the partial fusion protein (F) gene sequence of local isolates of $h M P V$, the fusion protein $(F)$ gene has several characteristics that made it the best gene to analyze the genotyping of $h M P V$, first of all, the $F$ gene is more conserved than other genes, rather than it encodes a 539 - amino acids, protein, this length of putative fusion protein ORF is neither so short such as M2-2 protein, 71 , nor so long such as L protein which is 2005 in length; therefore, the analysis comparison is adequate to determine the genetic diversity of $h M P V$, the analysis sequence of $h M P V$ relies on sequencing of the otherwise genes such as $N, M, G$, and $L$ is the genotype grouping and is concordant anyhow of which is studied $[5,15,16]$. In addition, there is another important feature, the F-protein is capable of provoking the immune response and producing a potent immunoglobulin that neutralizes the virus and regardless of majorly homologous, the cross-productivity can occur $[17,18]$. However, depending on genetic sequencing of $h M P V$ and construction of phylogenetic tree [Table 4], there are two main genotypes of $h M P V$ which labeled $h M P V-A$ and $h M P V-B$, likewise, these genotypes also separated into two sublineages as $\mathrm{A} 1$ and $\mathrm{A} 2$ so $\mathrm{B} 1$ and $\mathrm{B} 2$. In the current study, nucleotides sequencing was gained from $5(5 / 100,5 \%) h M P V$ positive samples. Amplified products are elected to concede to the partial genome sequencing of the $F$ gene for determination of the local isolates of $h M P V$ subtypes, the income of these sequencing is two genotypes $\mathrm{A}$ and $\mathrm{B}, \mathrm{HPV}$ ) genotype $\mathrm{A} 1$ is found in $1 / 5,20 \%, \mathrm{~A} 2$ is not existing in the current study, and B1 is present in $3 / 5,60 \%$ and B2 $1 / 5,20 \%$, additionally, the homology of local current isolates was $100 \%$ of hMPV-S1, hMPV-S3, at the nucleotides sequencing level with the KM408076.1 and KJI96323.1, respectively, and 99\% of hMPV-S4 with JQ041689.1 strain, three of five $h M P V-S 2, S 3$, and $h M P V$ were identical $(100 \%)$. Therefore, the 
Table 4: DNA homology sequence identity using NCBI- BLAST alignment tool

\begin{tabular}{lllll}
\hline \multirow{2}{*}{ Local $\boldsymbol{h}$ MPV } & \multicolumn{4}{l}{ Homology sequence identity (\%) } \\
\cline { 2 - 5 } & hMPV Genotype & hMPV Genotype & hMPV Genotype & hMPV Genotype \\
& A1 (KM408076.1) & A2 (KJ196309.1) & B1 (KJ196323.1) & B2 (JQ041689.1) \\
\hline$h M P V-S 1$ & $100 \%$ & $91 \%$ & $93 \%$ & $89 \%$ \\
$h M P V-S 2$ & $86 \%$ & $86 \%$ & $100 \%$ & $94 \%$ \\
$h M P V-S 3$ & $86 \%$ & $86 \%$ & $100 \%$ & $94 \%$ \\
$h M P V-S 4$ & $86 \%$ & $85 \%$ & $93 \%$ & $99 \%$ \\
$h M P V-S 5$ & $86 \%$ & $86 \%$ & $100 \%$ & $94 \%$ \\
\hline
\end{tabular}

HMPV: Human metapneumovirus

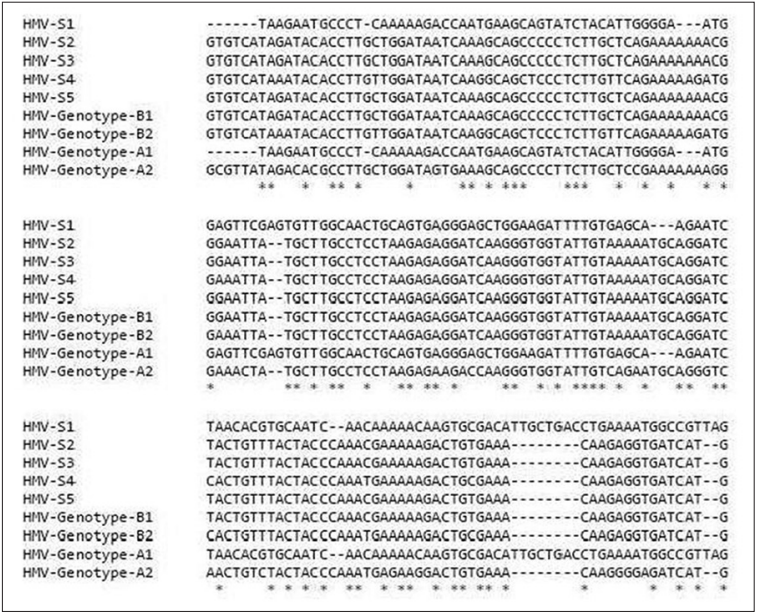

Fig. 4: Multiple sequence alignment analysis of the partial fusion protein (F) gene sequence in local human metapneumovirus isolates with for N C B I -GenBank human metapneumovirus based C 1 u s $t$ a $1 \mathrm{~W}$ alignment analysis by using (MEGA 6 . 0 , $\mathrm{m}$ u $\mathrm{lt}$ i p $\mathrm{l}$ e alignment analysis tools). The multiple alignment analysis similarities $(*)$ and differences in fusion protein $(F)$ gene nucleotide sequences

genotype B is predominant (80\%), the predominance rate of $h M P V$ is problematic and dynamic, MPV's strains unlikely the influenza viruses which responsible for a global pandemic due to exhibits swift genetic evolution through the antigenic shift and antigenic drift, while $h M P V$ reveals 2-3 worldwide spread annually. The outbreak of $h M P V$ demonstrates to be a local occurrence [19], however, RNA viruses reveal a genetic mutation frequently because of this RNA virus absence of proofreading capability of RNA-dependent RNA polymerase [20].

In comparison with other studies that have been accomplished in every continent, have shown distinctive proportional than current study, $h M P V$ strains display fluctuation starting from one population to another, additionally, pick $h M P V$ strains in one population may be likely to strains that observed in somewhere else in various seasons. Nor'E et al. have shown that the Malaysian isolates of $h M P V$ grouped predominantly into two sublineages, A2b (54\%) and B1 (42\%), of the same study, B1 is predominant in 2012, makeup 9/11 (81.8\%) of the strains. Another study as that done by Liat et al., have displayed only one subgenotype A2 was obtainable, furthermore, another study that's done by Qaisy et al., in Jorden, the lineage A was detected in $93 \%$, while $28.6 \%$ with the lineage B. Although these previous studies differ from the current study in recognition and analyzing of the predominant genotype there are anther studies have revealed the similar genotype, which has recognized in this study, as the research that has achieved in Upper Egypt by Mohamed et al. which displayed the subgroup B2 was predominant. Similar to this result, in Cambodia between 2007 and 2008, [10] they observed that the sublineage B2 strain is predominant. However, reemerged and recirculation of genotype and sublineage have been observed to differ every year, which are substituted each 1 to 3 years inside a particular community, and it is believed to happen to rely on particular improvement of acquired immunity to the infected strain of the predominant coursing genotype [25-28].

The phylogenetic tree was constructed using Maximum Likelihood tree method in MEGA 6.0 version. The local HMV isolates (S1) showed closed related to NCBI-Blast human metapneumovirus genotype A1 (KM408076.1), the local $h M P V$ isolates (S2, S3, and S5) were closely related to NCBI- Blast human metapneumovirus genotype B1 (KJ196323.1), and the local $h M P V$ isolates (S4) were closely related to NCBI-Blast human metapneumovirus genotype B2 (JQ041689.1) [29].

\section{CONCLUSION}

The prevalence rate of $h M P V$ is less than a respiratory syncytial virus, and both subtypes of $h M P V, \mathrm{~A}$ and B may exist and circulate in one season, and the predominant sublineage of $h M P V$ shifts in progressive season. The genotypes of $h M P V, \mathrm{~A} 1, \mathrm{~A} 2, \mathrm{~B} 1$, and $\mathrm{B} 2$ are prevalently varied, and they do reveal different to other isolates of other places in the world, these genetic diversities of $h M P V$ strains produces recurrent infection and subterfuge a challenge for future vaccine development.

\section{ACKNOWLEDGMENTS}

The authors wish to thank the technical staff of College of Medicine/ University of Al-Qadisiyah/Iraq, for several support during this research, they contributed correspondingly to work.

\section{REFERENCES}

1. van den Hoogen BG, Herfst S, Sprong L, Cane PA, Forleo-Neto E, de Swart RL, et al. Antigenic and genetic variability of human metapneumoviruses. Emerg Infect Dis 2004;10:658-66.

2. Boivin G, Abed Y, Pelletier G, Ruel L, Moisan D, Côté S, et al. Virological features and clinical manifestations associated with human metapneumovirus: A new paramyxovirus responsible for acute respiratory-tract infections in all age groups. J Infect Dis 2002;186:1330-4.

3. Bosis S, Esposito S, Niesters HG, Crovari P, Osterhaus AD, Principi N, et al. Impact of human metapneumovirus in childhood: Comparison with respiratory syncytial virus and influenza viruses. J Med Virol 2005;75:101-4.

4. Schildgen V, van den Hoogen B, Fouchier R, Tripp RA, Alvarez R, Manoha C, et al. Human metapneumovirus: Lessons learned over the first decade. Clin Microbiol Rev 2011;24:734-54.

5. Peret TC, Boivin G, Li Y, Couillard M, Humphrey C, Osterhaus AD, et al. Characterization of human metapneumoviruses isolated from patients in north america. J Infect Dis 2002;185:1660-3.

6. Collins PL, Mottet G. Membrane orientation and oligomerization of the small hydrophobic protein of human respiratory syncytial virus. J Gen Virol 1993;74 (Pt 7):1445-50.

7. Easton AJ, Domachowske JB, Rosenberg HF. Animal pneumoviruses: Molecular genetics and pathogenesis. Clin Microbiol Rev 2004; 17:390-412.

8. Kahn JS, Kesebir D, Cotmore SF, D’Abramo A Jr., Cosby C, Weibel C, et al. Seroepidemiology of human bocavirus defined using recombinant virus-like particles. J Infect Dis 2008;198:41-50.

9. Papenburg J, Boivin G. The distinguishing features of human metapneumovirus and respiratory syncytial virus. Rev Med Virol 2010;20:245-60. 
10. Arnott A, Vong S, Sek M, Naughtin M, Beauté J, Rith S, et al. Genetic variability of human metapneumovirus amongst an all ages population in cambodia between 2007 and 2009. Infect Genet Evol 2013;15:43-52.

11. Maggi F, Pifferi M, Vatteroni M, Fornai C, Tempestini E, Anzilotti S, et al. Human metapneumovirus associated with respiratory tract infections in a 3-year study of nasal swabs from infants in italy. J Clin Microbiol 2003;41:2987-91.

12. Kuypers J, Wright N, Corey L, Morrow R. Detection and quantification of human metapneumovirus in pediatric specimens by real-time RT-PCR. J Clin Virol 2005;33:299-305.

13. Sarasini A, Percivalle E, Rovida F, Campanini G, Genini E, Torsellini M, et al. Detection and pathogenicity of human metapneumovirus respiratory infection in pediatric italian patients during a winter-spring season. J Clin Virol 2006;35:59-68.

14. Junior JB, Gardinassi LG, Simas PV, Bittar CO, Souza FP, Rahal P, et al. Human respiratory syncytial virus in children hospitalized for acute lower respiratory infection. J Pediatr (Rio J) 2011;87:219-24.

15. Bastien N, Normand S, Taylor T, Ward D, Peret TC, Boivin G, et al. Sequence analysis of the N, P, M and F genes of canadian human metapneumovirus strains. Virus Res 2003;93:51-62.

16. Biacchesi S, Pham QN, Skiadopoulos MH, Murphy BR, Collins PL, Buchholz UJ, et al. Infection of nonhuman primates with recombinant human metapneumovirus lacking the $\mathrm{SH}, \mathrm{G}$, or $\mathrm{M} 2-2$ protein categorizes each as a nonessential accessory protein and identifies vaccine candidates. J Virol 2005;79:12608-13.

17. Ulbrandt ND, Ji H, Patel NK, Barnes AS, Wilson S, Kiener PA, et al. Identification of antibody neutralization epitopes on the fusion protein of human metapneumovirus. J Gen Virol 2008;89:3113-8.

18. Ryder AB, Tollefson SJ, Podsiad AB, Johnson JE, Williams JV. Soluble recombinant human metapneumovirus $\mathrm{G}$ protein is immunogenic but not protective. Vaccine 2010;28:4145-52.

19. Esper F, Martinello RA, Boucher D, Weibel C, Ferguson D, Landry ML, et al. A 1-year experience with human metapneumovirus in children aged $<5$ years. J Infect Dis 2004;189:1388-96.
20. Drake JW. Rates of spontaneous mutation among RNA viruses. Proc Natl Acad Sci U S A 1993;90:4171-5.

21. Nor'e SS, Sam IC, Mohamad Fakri EF, Hooi PS, Nathan AM, de Bruyne JA, et al. Phylogenetic analysis of human metapneumovirus among children with acute respiratory infections in kuala lumpur, malaysia. Trop Biomed 2014;31:562-6.

22. Liat HL, Boon HT, Ley MN, Tee NW, Lin RT, Sugrue RJ. Human metapneumovirus in children, Singapore. Emerg Infect Dis 2007; $13: 1396-8$

23. Qaisy LM, Meqdam MM, Alkhateeb A, Al-Shorman A, Al-Rousan HO, Al-Mogbel MS, et al. Human metapneumovirus in jordan: Prevalence and clinical symptoms in hospitalized pediatric patients and molecular virus characterization. Diagn Microbiol Infect Dis 2012;74:288-91.

24. Mohamed MS, Reiche J, Jacobsen S, Thabit AG, Badary MS, Brune W, et al. Molecular analysis of human metapneumovirus detected in patients with lower respiratory tract infection in upper egypt. Int $\mathrm{J}$ Microbiol 2014;2014:290793.

25. Aberle JH, Aberle SW, Redlberger-Fritz M, Sandhofer MJ, PopowKraupp T. Human metapneumovirus subgroup changes and seasonality during epidemics. Pediatr Infect Dis J 2010;29:1016-8.

26. Carneiro BM, Yokosawa J, Arbiza J, Costa LF, Mirazo S, Nepomuceno LL, et al. Detection of all four human metapneumovirus subtypes in nasopharyngeal specimens from children with respiratory disease in uberlândia, brazil. J Med Virol 2009;81:1814-8.

27. Dakhil AS. Biosynthesis of silver nanoparticle (AgNPs) using Lactobacillus and their effects on oxidative stress biomarkers in rats. J King Saud Univ Sci 2017. DOI: 10.1016/j.jksus.2017.05.013.

28. Williams JV, Harris PA Tollefson SJ, Halburnt-Rush LL, Pingsterhaus JM, Edwards KM, et al. Human metapneumovirus and lower respiratory tract disease in otherwise healthy infants and children. N Engl J Med 2004;350:443-50.

29. Al-saeed MS, Muhsin MA, Al-juburi GJ. Study the role of Toxoplasma gondii, cytomegalovirus and anti-phospholipids antibodies in cases of abortion among women in Hilla city. Al-Qadisiyah Med J 2008;4:27-34. 